Article

\title{
Addition of Broad Bean Hull to Wheat Flour for the Development of High-Fiber Bread: Effects on Physical and Nutritional Properties
}

\author{
Qianqian Ni, Viren Ranawana, Helen E. Hayes ${ }^{(D)}$, Nicholas J. Hayward ${ }^{D}$, David Stead and \\ Vassilios Raikos*(D) \\ Rowett Institute, University of Aberdeen, Aberdeen AB25 2ZD, UK; q.ni.18@abdn.ac.uk (Q.N.); \\ vranawana@abdn.ac.uk (V.R.); h.hayes@abdn.ac.uk (H.E.H.); n.j.hayward@abdn.ac.uk (N.J.H.); \\ d.stead@abdn.ac.uk (D.S.) \\ * Correspondence: v.raikos@abdn.ac.uk; Tel.: +44-01224-438581
}

Received: 23 July 2020; Accepted: 25 August 2020; Published: 28 August 2020

check for updates

\begin{abstract}
The seed coat (hull) of broad bean (Vicia faba) (BBH) is a significant secondary product of processing with a promising nutritional profile. Bean hull has a high fiber content (49\%), yet it remains underexploited as an ingredient by the food industry. This study investigated the potential of this secondary product to partially replace wheat flour for the development of high-fiber breads. Bread formulations with a range of supplementation levels $(0 \%, 11 \%, 21 \%$ and $31 \%)$ were developed and tested for their nutritional and physical properties. The proximate composition of breads revealed that at $31 \%$ replacement, the fiber content was $19.19 \mathrm{~g} / 100 \mathrm{~g}$ bread, which was significantly higher $(p<0.05)$ than control breads $(3.62 \mathrm{~g} / 100 \mathrm{~g}$ bread). The physical (specific volume, density and color) and textural properties of breads were affected by the addition of bean hull. Specific volume and hardness of breads were significantly reduced at $\geq 21 \%$ replacement compared to the control, which may reduce acceptability of the product by some consumer groups. Enzyme-linked immunosorbent assay (ELISA) showed that the gluten content of breads was significantly reduced with bean hull addition (62\% depletion for $31 \%$ replacement). At $11 \%, 21 \%$ and $31 \%$ replacement, one portion $(80 \mathrm{~g}$ of bread) contains $6.8 \mathrm{~g}, 11.6 \mathrm{~g}$ and $15.3 \mathrm{~g}$ of dietary fiber, respectively, which contributes $23 \%, 38 \%$ and $51 \%$ of the recommended daily fiber intake (30 g/day). In conclusion, bean hull can be a valuable source of dietary fiber in bread formulations. The study showed BBH could be used to replace up to $21 \%$ of the wheat flour without significantly impacting on bread texture and volume.
\end{abstract}

Keywords: broad bean hull; Vicia faba; bread; gluten; high fiber; texture

\section{Introduction}

Bread is an important staple food worldwide, which is typically made from wheat (Triticum aestivum) flour, salt, sugar, water, fat and baker's yeast. Wheat flour is a key ingredient in bread making due to its unique endosperm protein composition (gliadins and glutenins). The latter are responsible for the formation of "gluten", which is the term commonly used to describe the viscoelastic network of the dough that allows the entrapment of $\mathrm{CO}_{2}$ and contributes to the desired bread texture and volume [1]. Food products made of wheat contribute significantly towards meeting dietary energy and protein intakes, and therefore their moderate consumption (250-350 g of bread daily) is recommended by nutritional bodies [2]. The majority of wheat flour used for bread making is refined due to consumer demands. However, the refinement process diminishes nutritional quality, particularly in its fiber, vitamin and phytochemical contents [3]. To compensate for these nutritional losses, a multi-grain approach is often adopted by the baking industry. This approach uses refined 
wheat flour in combination with nutrient-dense flours from other crops to improve the nutritional profile of the end-product and meet consumer demands for healthier food products [4].

The important role of dietary fiber (DF) in disease prevention has become increasingly apparent in recent years. Its beneficial effects on human health include reduced risk of coronary heart disease, diabetes and colon cancer [5,6], and are attributed to the physicochemical and functional properties of fiber. The daily recommendations for DF ( $30 \mathrm{~g} /$ day) are not met by the majority of the adult population in westernized countries. Thus, the incorporation of DF into frequently consumed processed foods could be an effective approach for meeting recommendations and satisfying consumer demands for more nutritious food products.

Broad bean (Vicia faba; field bean, horse bean, fava bean) is a legume belonging to the family Fabaceae and forms an important part of diets in many parts of the world, notably in Middle Eastern, Mediterranean, Asian, South American and African regions. As a leguminous crop it is often used in crop rotation for soil enrichment. The principle dietary element of the plant is the seed, which is consumed fresh and dried, and similar to other legumes has a favorable nutritional profile rich in protein, fiber, micronutrients and phytochemicals [7]. The processing of combinable broad beans involves the removal of the seed testa (hull) constituting approximately $12-14 \%$ of seed weight, as this is believed to improve eating quality and appearance. Therefore, the hull is a significant secondary product of bean processing which is largely underutilized. Previous research indicates dehulling significantly reduces the total non-starch polysaccharide (NSP) content in the coarse fractions of broad beans, thus affecting the dietary fiber content in the legume post-processing [8].

Little work has been carried out to assess the potential of secondary products derived from broad bean processing as a human food despite it being a food grade material that is rich in fiber and phytochemicals. Previous work shows that fiber from broad bean pods can be used to enhance dough development and to improve the textural profile of bread [9]. Data gathered by our group over the last two years show that broad bean hull has a favorable nutritional profile compared to comparable material such as wheat bran. The aim of this study was to assess the potential of using broad bean hull (BBH) for developing high-fiber breads. The effect of white flour partial replacement with BBH on bread quality (volume, texture, color) and nutritional composition was investigated.

\section{Materials and Methods}

\subsection{Materials}

White flour (Tesco Stores Ltd., Welwyn Garden City, UK), yeast (Allinson's Flour, Peterborough, UK), Trex vegetable fat (Princes Limited, Liverpool, UK) and Saxa fine sea salt (Premier Foods, Cheshire, UK) were purchased from a local supermarket (Tesco, Aberdeen, UK). Broad bean hull (variety 'Fuego') was kindly provided by Askew and Barrett (Pulses) Ltd. (Cambs, UK). The hull was obtained through a standard legume processing methodology in a commercial large-scale plant. Briefly, following sampling and inspection dry broad beans were destoned and defected seeds and foreign material removed. The beans were colour sorted and dehulled using a Berhard Keller abrasion dehuller. The resulting hull was sieved to remove excess cotyledon particles, and then milled to a particle size of below $0.5 \mathrm{~mm}$ using a rotor mill fitted with a $0.5 \mathrm{~mm}$ sieve (ZM 20, Retsch, Haan Germany) at the James Hutton Institute (Dundee, UK). All reagents used were of analytical grade.

\subsection{Bread Preparation}

Control breads was prepared using $100 \%$ wheat flour. All dry ingredients (including salt) were combined with water manually until a cohesive dough was formed and rested for ten min before kneading for five min by hand. Treatment breads were made by replacing $11 \%, 21 \%$ and $31 \%$ of the white flour with $\mathrm{BBH}$ and the water content and salt were adjusted accordingly (Table 1). After kneading, the dough was covered with a damp cloth and proofed for $90 \mathrm{~min}$ at room temperature. After the first proofing, the dough was divided into two (each dough weighed $175 \mathrm{~g}$ ), weighed and proofed 
again for $60 \mathrm{~min}$ at room temperature. The rolls were baked in a pre-heated fan-assisted oven at $200^{\circ} \mathrm{C}$ for $23 \mathrm{~min}$, cooled at room temperature for $1.5 \mathrm{~h}$ and their weights recorded before storing at $4{ }^{\circ} \mathrm{C}$ overnight prior to physical and nutritional analysis.

Table 1. Formulations for control and broad bean hull (BBH) enriched breads.

\begin{tabular}{cccccc}
\hline \multirow{2}{*}{ Ingredient } & Control & $\mathbf{1 1 \%}$ & $\mathbf{2 1 \%}$ & $\mathbf{3 1 \%}$ & \multirow{2}{*}{ \% of Flour } \\
\cline { 2 - 4 } & \multicolumn{5}{c}{ Quantity $\mathbf{( g )}$} \\
\hline Strong white wheat flour & 75 & 75 & 75 & 75 & - \\
BBH & - & 9 & 20 & 34 & 3 \\
Yeast & 2 & 2 & 2 & 2 & 2 \\
Salt & 1.4 & 1.7 & 1.8 & 2.2 & 5 \\
Fat & 3.75 & 3.75 & 3.75 & 3.75 & 78.9 \\
Water (lukewarm) & 59 & 66 & 75 & 86 & \\
\hline
\end{tabular}

The weights of the above ingredients were tripled for control, $11 \%$ and $21 \%$, and those of $31 \%$ were doubled to obtain two equivalent doughs of $175 \mathrm{~g}$. The percentages given for salt and water account for total dry powder (\% dry powder).

\subsection{Physical Properties}

\subsubsection{Specific Volume, Density and Weight Loss}

Bread volume was determined using a modified standard rapeseed displacement method 10-05 (American Association of Cereal Chemists (AACC) International, 2000) [10], in which sesame seeds were used instead of rapeseed. The loaf specific volume was calculated as loaf volume divided by loaf weight (1.5 h after baking). Density was calculated as loaf weight divided by loaf volume. Weight loss was computed as below:

$$
\text { Weight loss }(\%)=\frac{(\text { initial weight before baking }- \text { loaf weight } 1.5 \mathrm{~h} \text { after baking }) \times 100}{\text { initial weight before baking }}
$$

\subsubsection{Bread Crust and Crumb Color}

Crust and crumb color were measured by a Konica Minolta CR1 10 color meter (Konica Minolta Solutions Ltd., Basildon, UK). Breads were sliced using a Swan food slicer (model SFS102, adjusted to $15 \mathrm{~mm}$ thickness), crust color measured at the middle point of the top crust of bread, and crumb color measured at the middle point of the central slice in triplicate under controlled lighting. Measurements were made using the International Commission on Illumination (CIE) $L^{*}$ (lightness), $a^{*}$ (redness to bluishness), $b^{*}$ (yellowness to greenness) system. Brownness index (BI) and whiteness index (WI) were calculated as follows [11]:

$$
B I=\frac{(100(X-0.31))}{0.17}
$$

where, $X=\frac{(a *+1.75 L *)}{\left(5.645 L^{*}+a *-3.012 b *\right)}$.

$$
W I=100-\left((100-L *)^{2}+a *^{2}+b *^{2}\right)^{1 / 2}
$$

\subsection{Texture Analysis}

For each bread, the middle slice and the two slices on either side of it were used for texture profile analysis (TPA) $24 \mathrm{~h}$ after baking using a CT3 Texture Analyser (Brookfield Engineering Laboratories, Inc., Middleboro, MA, USA) fitted with a cylinder probe (TA11/1000, diameter $=25.4 \mathrm{~mm})$. Data was recorded using Texture Proc CT V1.3 Build 15 software (Brookfield Engineering Laboratories Inc.). All measurements were made in duplicate at a pre-test speed of $2 \mathrm{~mm} / \mathrm{s}$, test speed of $1 \mathrm{~mm} / \mathrm{s}$, trigger 
force of $10 \mathrm{~g}$, and 50\% compression [9]. The texture properties determined were hardness, resilience, adhesiveness, cohesiveness, springiness and chewiness.

\subsection{Scanning Electron Microscopy (SEM)}

Bread samples were freeze dried and manually fractured into cubes using the tip of a razor blade. Samples were made electrically conductive by coating with a thin layer of gold-palladium using a Quorum Q150 ES sputter coater (Quorum Technologies Ltd., East Sussex, UK). BBH sample was sprinkled on to the stub used to display the sample and then treated with the gold. The samples were imaged at an accelerating voltage of $10 \mathrm{kV}$ using a Zeiss EVO MA10 SEM (Carl Zeiss Ltd., Cambridge, UK). SEM pictures of the newly exposed surface of BBH were taken at $200 \times$ and $1000 \times$ magnifications and those of bread samples were taken at $1000 \times$ and $3000 \times$.

\subsection{Nutritional Analysis}

\subsubsection{Proximate Composition Analysis of BBH Powder and Breads}

The proximate composition of BBH powder and breads was analysed in duplicate using standard Association of Official Analytical Chemists (AOAC) analytical procedures [12]. Dietary fiber (DF) was determined by general method AOAC 991.43, which is the enzymatic-gravimetric method most used in determining the DF content of foods [13]. Non-starch polysaccharides (NSP) were determined by the Englyst method [14]. These analyses were conducted by a United Kingdom Accreditation Service (UKAS) certified testing facility (Huson and Hardwick's Food Test Lab, Merseyside, England) and accredited to ISO 17025:2017.

\subsubsection{Gluten Quantification}

The gluten content of each sample was analysed using the AgraQuant ${ }^{\circledR}$ Gluten G12 ${ }^{\circledR}$ Assay (AACC International Method 38-52.01) (Romer Labs UK Ltd., Runcorn, Cheshire, UK). Samples were extracted in duplicate according to the manufacturer's standard method. Briefly, samples were blended by a blender (Essex Scientific Laboratory Supplies Ltd., Essex, UK) for about five min and $0.25 \mathrm{~g}$ weights were mixed with $2.5 \mathrm{~mL}$ of extraction solution before incubating at $50{ }^{\circ} \mathrm{C}$ for $40 \mathrm{~min}$. This was followed by the addition of $7.5 \mathrm{~mL}$ of $80 \%$ ethanol and agitation for $60 \mathrm{~min}$ at room temperature, and centrifuged at $2000 \times g$ for ten min. The clear aqueous layer between the particulate sediment and supernatant was obtained and stored at $4{ }^{\circ} \mathrm{C}$ until analysis. The extracted bread samples were diluted to 1:5000 and 1:10,000 with diluent buffer and loaded on to antibody coated microwells in duplicate along with gluten standards $(0,4,20,80$ and $200 \mathrm{ppm})$ before analysis.

\subsection{Statistical Analysis}

Statistical analysis was performed by SPSS software version 25.0 (SPSS for Windows 22, SPSS Inc., Chicago, IL, USA). Data on the physical properties, texture analysis, proximate analysis and gluten content were analyzed by one-way ANOVA and using post-hoc Tukey tests where significant model effects were observed. Statistical significance was defined as $p<0.05$, and results expressed as means and standard deviations (SD).

\section{Results and Discussion}

\subsection{Physical Properties}

\subsubsection{Specific Volume, Density and Weight Loss}

All bread loaves were made using a standard bread making process which included mixing, fermentation and baking. The visual appearances and dimensions of all bread loaves and slices are shown in Figure 1. The 31\% BBH bread loaf size was the smallest whilst the control bread was the 
largest. The control bread slice and $11 \%$ BBH bread slice presented similar visual appearance. When the fortification level was higher than $11 \%$, the crumb surface was darker and presented smaller porous structure compared with the control bread.

The results of specific volume, density and weight loss are shown in Table 2. The specific volume is the most important parameter in bread making, which indicates final gas retention in the bread and affects consumer preference. The control bread had the greatest specific volume $(4.11 \pm 0.08 \mathrm{~mL} / \mathrm{g})$. The specific volumes of $\mathrm{BBH}$ fortified breads varied from 1.65 to $3.65 \mathrm{~mL} / \mathrm{g}$ and were significantly lower compared to the control $(p<0.05)$. This loss of volume can be attributed to the dilution of gluten content and the increase in fiber content of BBH. Fiber particles can impede proper gluten development by cutting through gluten strands, thus inhibiting the formation of a viscoelastic network, which results in weakening of the dough $[15,16]$. A weakened gluten network during dough formation can hinder rising of the bread which results in decreased loaf volume.

Breads at $31 \%$ fortification level had the highest density $(0.61 \pm 0.02 \mathrm{~g} / \mathrm{mL})$ whereas the control bread was the least dense $(0.24 \pm 0.004 \mathrm{~g} / \mathrm{mL})$, and the density was significantly increased while increasing the BBH fortification level $(p<0.05)$. Previous research has shown that fiber can modify food structure and increase its density because of its fibrous nature [17]. Additionally, the highest weight loss was observed in the control breads $(13.79 \pm 0.59 \%)$, while it decreased gradually with addition of $\mathrm{BBH}$, and only significant differences among control, $21 \%$ and $31 \%$, as well as between $11 \%$ and $31 \%$ breads were observed $(p<0.05)$. This is possibly because fiber is rich in non-starch polysaccharides (NPS's) which can bind to water through the formation of hydrogen bonds [18]. Fiber tends to absorb water which limits water availability for other key ingredients in gluten development such as gluten and starch. There are two main effects of fiber on bread structure: it allows more water to be absorbed within the bread structure and alters dough development [19]. This latter is manifested by prolonged mixing time, longer dough development time and reduced extensibility in fiber-rich dough [20]. Previous research revealed that pan bread fortified with rice bran had lower baking loss [21]. The authors suggest that the high fiber content of rice bran induced water interactions through the formation of hydrogen bonds resulting in lower baking losses. 

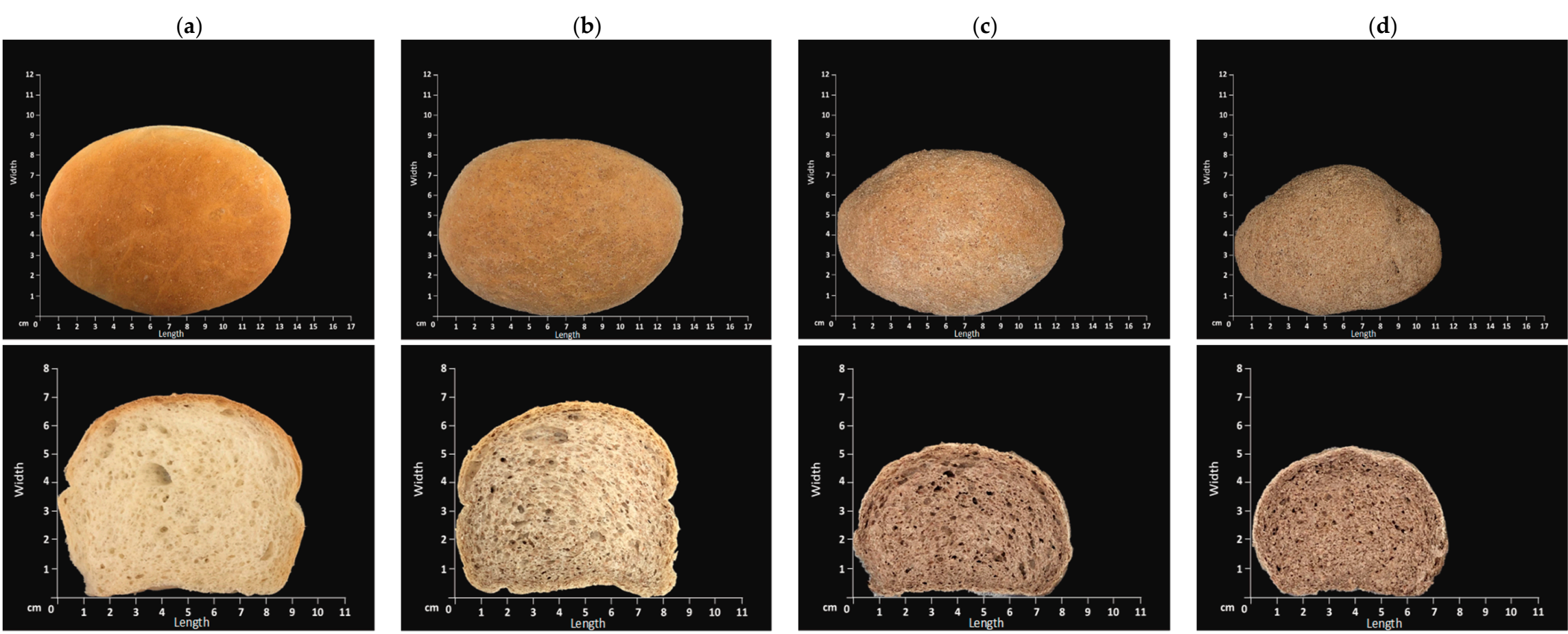

Figure 1. Loaves and slices of bread samples: (a) control; (b) $11 \% \mathrm{BBH}$ bread; (c) $21 \% \mathrm{BBH}$ bread; (d) $31 \% \mathrm{BBH}$ bread.

Table 2. Physical characteristics of control bread, $11 \%, 21 \%$ and $31 \%$ of $\mathrm{BBH}$ fortified breads.

\begin{tabular}{|c|c|c|c|c|c|c|c|c|c|}
\hline \multirow{3}{*}{ Bread Type } & \multirow{3}{*}{ Specific Volume $(\mathrm{ml} / \mathrm{g})$} & \multirow{3}{*}{ Density (g/mL) } & \multirow{3}{*}{ Weight Loss (\%) } & \multicolumn{6}{|c|}{ Colour } \\
\hline & & & & \multicolumn{3}{|c|}{ Crust } & \multicolumn{3}{|c|}{ Crumb } \\
\hline & & & & $\mathrm{L}^{*}$ & WI & BI & $\mathbf{L}^{*}$ & WI & BI \\
\hline Control & $4.11 \pm 0.08^{a}$ & $0.24 \pm 0.004^{\mathrm{a}}$ & $13.79 \pm 0.59^{a}$ & $51.90 \pm 2.12^{a}$ & $40.07 \pm 1.71^{\mathrm{a}}$ & $113.52 \pm 6.13^{a}$ & $62.65 \pm 1.18^{a}$ & $59.91 \pm 1.07^{a}$ & $26.75 \pm 0.69^{a}$ \\
\hline $21 \%$ & $2.30 \pm 0.03^{c}$ & $0.44 \pm 0.01^{c}$ & $11.61 \pm 0.51 \mathrm{bc}$ & $55.25 \pm 0.77^{b}$ & $51.29 \pm 1.03^{c}$ & $48.15 \pm 3.22^{c}$ & $35.55 \pm 4.40^{\mathrm{c}}$ & $34.25 \pm 4.33^{c}$ & $51.74 \pm 8.46^{b}$ \\
\hline $31 \%$ & $1.65 \pm 0.05^{d}$ & $0.61 \pm 0.02^{d}$ & $11.17 \pm 0.91^{\mathrm{c}}$ & $43.47 \pm 1.32^{\mathrm{c}}$ & $41.56 \pm 1.22^{a}$ & $46.88 \pm 1.06^{\mathrm{c}}$ & $40.67 \pm 1.50^{\mathrm{d}}$ & $38.89 \pm 1.44^{\mathrm{d}}$ & $49.83 \pm 2.46^{b}$ \\
\hline
\end{tabular}

Data are expressed as mean \pm SD. WI is whiteness index: $100-\left[\left(100-L^{*}\right)^{2}+a^{* 2}+b^{* 2}\right]^{\frac{1}{2}}$; BI is brownness index: $[100 \times(X-0.31)] / 0.17$, where $X=\left(a^{*}+1.75 L^{*}\right) /\left(5.645 L^{*}+a^{*}-3.012 b^{*}\right)$

(Data for $\mathrm{a}^{*}$ and $\mathrm{b}^{*}$ are not shown). Different letters within each column represent significant differences $(p<0.05)$ in physical properties. 
BBH has a similar nutritional profile to wheat bran but higher DF content, particularly in insoluble fiber [22]. Table 3 shows that BBH is low in fat and carbohydrate content and contains approximately twice the amount of fiber compared to wheat bran ( $40 \mathrm{~g} / 100 \mathrm{~g})$ [23]. Furthermore, acid hydrolysis of the NSP revealed that the main monomeric sugars are glucose, xylose and uronic acid. It was reported that wheat bran fiber had a negative effect on the specific volume of bread as it produced less viscous dough which could not retain entrapped air bubbles during baking [24]. Adverse effects on dough properties due to the addition of bran to flour tend to increase with higher levels of wheat flour substitution with bran [25]. Numerous studies have shown a decrease in loaf volume after the addition of fibers from agricultural secondary products such as mango peels, pineapple pomace, apricot kernels and hazelnut testa [11,24-26]. In the current study, apart from lowering gluten content, BBH may also interfere with gluten structure resulting in reduced gas retention. Besides, it has been suggested that fiber can retain water during breadmaking and make it less available for development of the starch-gluten network [27].

Table 3. Proximate composition of $\mathrm{BBH}$ powder.

\begin{tabular}{ccc}
\hline Content & Broad Bean Hull \\
\hline Energy $($ kcal $)$ & 192 \\
Ash & 2.5 \\
Moisture & 9.0 \\
Protein & 5.3 \\
Fat & 0.4 \\
Carbohydrate & 1.1 \\
Fiber & 81.7 \\
\hline \multirow{4}{*}{ NSP } & Rhamnose & 0.4 \\
& Fucose & 0.1 \\
& Arabinose & 0.9 \\
Xylose & 10.0 \\
Mannose & 0.1 \\
Galactose & 0.8 \\
Glucose & 11.6 \\
Uronic acid & 8.5 \\
\hline
\end{tabular}

All values are per $100 \mathrm{~g}$ of sample. Unless otherwise stated units are in $\mathrm{g}$.

\subsubsection{Bread Crust and Crumb Color}

The results of bread crust and crumb color are shown in Table 2. Color is one of the most important parameters to determine bread quality and acceptability and is influenced by the Maillard reaction and caramelization during baking. The former involves reactions between reducing sugars and the free amino acid side chain of proteins which results in the formation of brown pigments [25]. The latter is a non-enzymatic reaction of sugars under high temperature [27].

In the current study, the lightness $\left(\mathrm{L}^{*}\right)$ of the crust color significantly increased at fortification levels $11 \%$ and $21 \%$ but decreased at $31 \%$. A similar trend was observed for the WI values of all fortified breads compared with the control bread. The BI of the control bread was the highest and then significantly dropped when the fortification level was above $11 \%$. There was no significant difference for BI between $21 \%$ and $31 \%$ breads. Although BBH imparted a brown color on the surface of the bread, the BI measured was significantly lower when compared with the control bread. One possible explanation for this may be associated with the decreased total sugar and protein content in breads fortified with BBH. Since the overall content of substrates for the Maillard reactions and caramelization is reduced, less brown pigment formation is expected.

Regarding crumb color, lightness was significantly decreased when BBH fortification was above $11 \%$. There was a significant decrease in WI for the BBH fortified breads. No significant difference was noted between the control and the $11 \%$ BBH bread but for samples at higher fortification levels $(\geq 21 \%)$, 
BI was significantly increased. However, the difference of BI was not significant between $21 \%$ and $31 \%$ breads. Since the temperature during baking is not above $100{ }^{\circ} \mathrm{C}$ inside the bread [28], the crumb color is determined by the colors of ingredients used to make the recipe [25]. These results indicate that incorporation of $\mathrm{BBH}$ into bread has darkening effects in the inner part of bread, which is attributed to the color effects imparted by the ingredients. Some studies also reported the darker crumb color of baking products after addition of DF enriched plant by-products [11,21,25].

\subsection{Texture Analysis}

Texture properties of all bread samples are presented in Table 4 . Hardness is the most important parameter which reflects bread quality. Compared with the control, BBH supplementation increased the hardness of breads, and this effect was significant $(p<0.05)$ for high levels of fortification $(31 \%)$. Similar results have been reported showing that the addition of plant-based secondary products rich in DF increased the hardness of breads $[11,24,25]$. This effect is attributed to the thickening of the walls surrounding the air cells in the crumb and is also associated with the formation of a cross-linked network between gluten proteins and starch [25]. Furthermore, DF interacts with gluten proteins and these interactions may be unfavorable for the formation of a viscoelastic dough [29].

Table 4. Texture properties of control bread, and $11 \%, 21 \%$ and $31 \%$ of $\mathrm{BBH}$ fortified breads.

\begin{tabular}{ccccccc}
\hline Bread Type & Hardness (g) & Resilience & Adhesiveness (mJ) & Cohesiveness & Springiness (mm) & Chewiness (mJ) \\
\hline Control & $558.67 \pm 37.19^{\mathrm{a}}$ & $0.28 \pm 0.02^{\mathrm{a}}$ & $0.47 \pm 0.34^{\mathrm{a}}$ & $0.54 \pm 0.02^{\mathrm{a}}$ & $7.19 \pm 0.20^{\mathrm{a}}$ & $21.17 \pm 1.62^{\mathrm{a}}$ \\
\hline $11 \%$ & $619.83 \pm 35.40^{\mathrm{a}}$ & $0.22 \pm 0.02^{\mathrm{b}}$ & $1.07 \pm 0.73^{\mathrm{ab}}$ & $0.47 \pm 0.05^{\mathrm{b}}$ & $7.32 \pm 0.18^{\mathrm{a}}$ & $21.08 \pm 3.21^{\mathrm{a}}$ \\
\hline $21 \%$ & $2100.83 \pm 344.69^{\mathrm{b}}$ & $0.13 \pm 0.01^{\mathrm{c}}$ & $1.18 \pm 0.89^{\mathrm{ab}}$ & $0.37 \pm 0.02^{\mathrm{c}}$ & $6.60 \pm 0.22^{\mathrm{b}}$ & $50.53 \pm 7.43^{\mathrm{b}}$ \\
\hline $31 \%$ & $4666.17 \pm 215.03^{\mathrm{c}}$ & $0.06 \pm 0.01^{\mathrm{d}}$ & $1.70 \pm 0.80^{\mathrm{b}}$ & $0.21 \pm 0.01^{\mathrm{d}}$ & $5.22 \pm 0.42^{\mathrm{c}}$ & $50.68 \pm 3.84^{\mathrm{b}}$ \\
\hline
\end{tabular}

Data are expressed as mean \pm SD. Means with different letters within each column are significantly different $(p<0.05)$.

Cohesiveness relates to the internal resistance of crumb structure and the ability of the crumb to deform before it fractures. Bread with low cohesiveness is susceptible to rupture [10]. There was a significant reduction of cohesiveness in $\mathrm{BBH}$ fortified breads compared to control breads. The $11 \% \mathrm{BBH}$ bread had the highest cohesiveness $(0.47 \pm 0.05)$ among all fortified breads. A high cohesiveness indicates an ability to form a bolus instead of crumbling during mastication. The reduction of cohesiveness in $\mathrm{BBH}$ fortified breads indicates they are more prone to disintegration during masticating.

Springiness is a measure of how much the crumb springs back after the first compression [30]. Chewiness is derived from springiness, hardness and cohesiveness and reflects the energy required to masticate food to a ready-to-swallow state [31]. Compared with control breads, $11 \%$ bread had similar springiness, but it significantly decreased at $21 \%$ and $31 \%$ BBH breads $(p<0.05)$. Chewiness of breads significantly increased when the supplementation level was above $21 \%$ and there was no difference between $21 \%$ and $31 \%$ BBH breads. Other research has also found that the addition of DF (wheat bran) could significantly increase chewiness but had no significant effect on springiness [21]. This is possibly because only $10 \%$ of wheat bran was used in their bread formulation, which contained less insoluble fiber compared with the present study.

By definition adhesiveness is the requirement of a force to remove breadcrumbs that adhere to the palate [21]. A significant increase of adhesiveness was observed between the control bread and all fortified breads. Adhesiveness and springiness can be used to indicate the elasticity of breads. This characteristic of breads is related to the interaction among gluten proteins, starch and water during breadmaking. This interaction was altered with the addition of DF as mentioned before and hence changed the texture of breads.

Resilience indicates the speed of crumb recovery after compression [32]. There was a significant decrease of resilience with increasing BBH in breads. The texture profile of bread samples indicates that the addition of $\mathrm{BBH}$ can affect their sensory properties by altering texture. This is likely to be due 
to the formation of a weakened gluten network structure, with adverse effects on texture observed at $31 \%$.

\subsection{SEM}

SEM was used to study the microstructure of the $\mathrm{BBH}$, control bread and $21 \% \mathrm{BBH}$ bread. The micrographs of BBH (Figure 2a) show the fiber structure in detail. Under 200× magnification, an irregularly shaped particle can be observed, which is similar in morphology to pea fiber microstructure [33]. When magnified to $1000 \times, \mathrm{BBH}$ presented as a polymeric network of densely packed elongated and fibrillar structures.

(a)
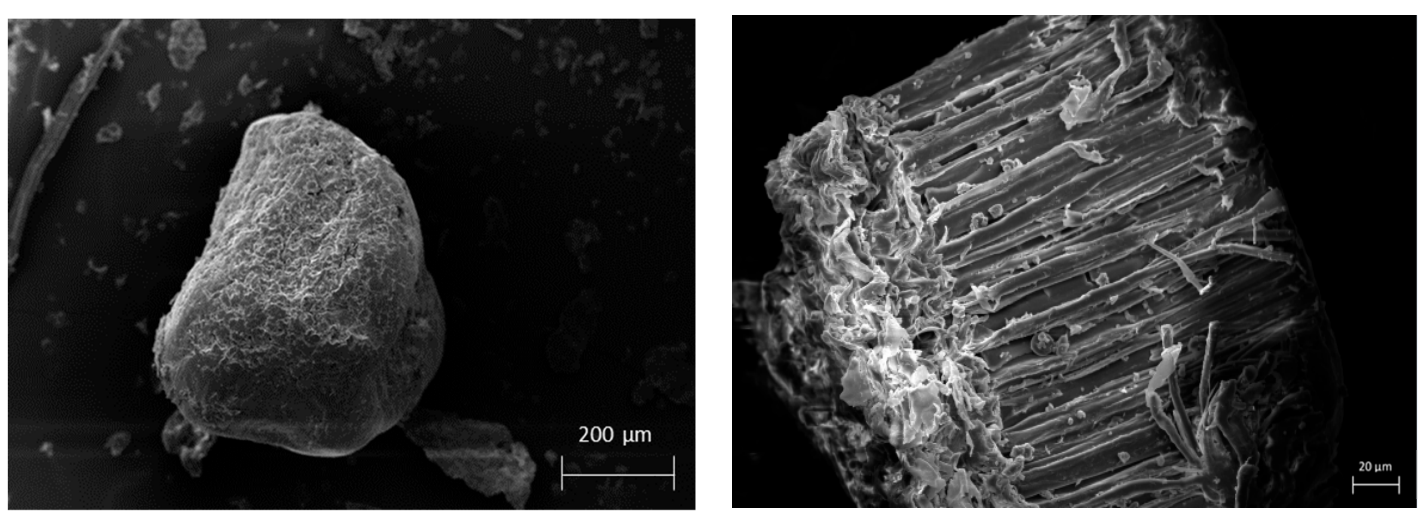

(b)
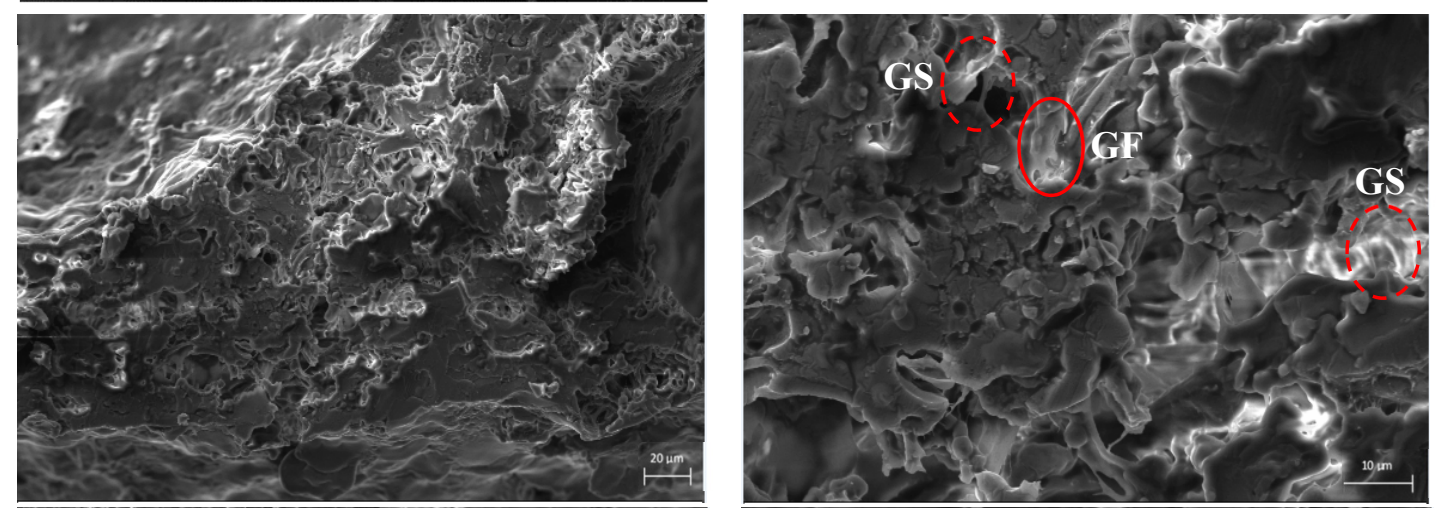

(c)
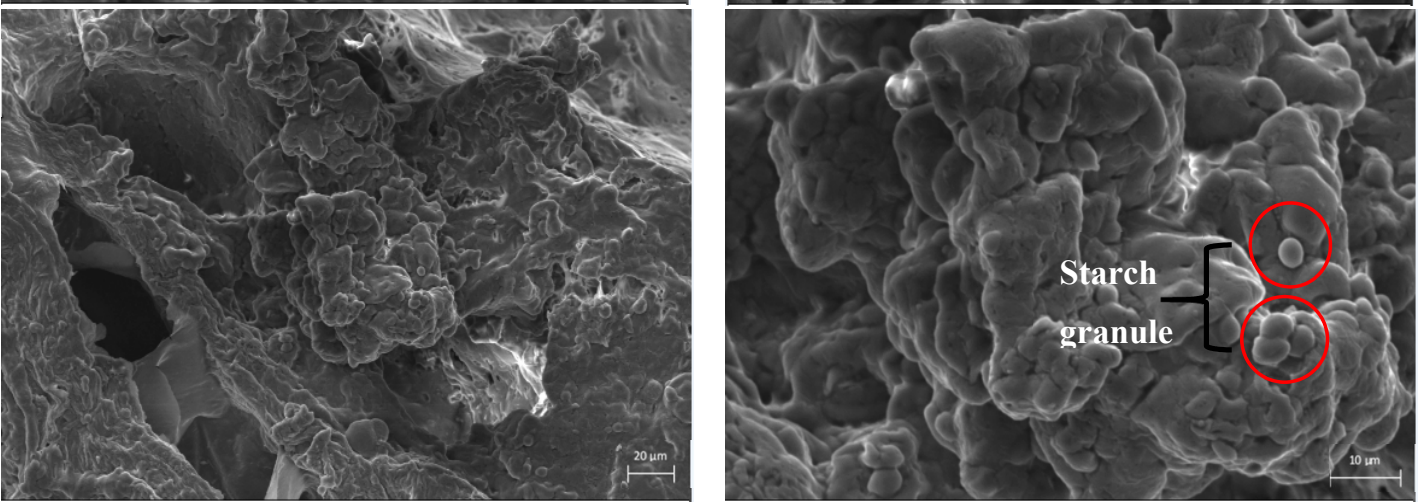

Figure 2. Microstructure of $\mathrm{BBH}$, control breads and $21 \% \mathrm{BBH}$ fortified bread. Scanning Electron Microscopy (SEM) was carried out at 200× and 1000× magnification in (a) BBH; 1000× and 3000× magnification in (b) control bread and (c) $21 \%$ BBH bread. GS, gluten strand; GF, gluten film.

Control bread (Figure $2 \mathrm{~b}$ ) had a rougher surface of crumb microstructure compared to the $21 \%$ $\mathrm{BBH}$ bread (Figure 2c) in 1000× magnification. Under 3000× magnification, control bread showed a rough layer with more gluten strands while $21 \% \mathrm{BBH}$ bread had a more continuous and smoother layer. Besides, 21\% bread tended to show naked starch granules whereas control bread had gluten films and 
appeared to be covered with intact starch granules. Those microstructure images support the hypothesis that there are interactions among gluten, starch and dietary fiber from BBH. Furthermore, the dilution of gluten proteins by starch may produce a weakened gluten network of reduced strength. The existence of increased starch granules can also produce an increasing number of gas cells, often surrounded by amorphous structures. Similar microstructure as the $21 \%$ BBH bread was observed in a high-protein hybrid bread which was formulated with broad bean, carob flour and psyllium [34]. Authors also suggested that the structure of the supplemented bread further supported the theory of a network among gluten, non-wheat proteins and fiber. Additionally, more naked starch granules were observed in a reduced-gliadin wheat dough microstructure [2].

\subsection{Nutritional Properties}

\subsubsection{Proximate Composition Analysis}

The results of the proximate composition of bread samples is shown in Table 5. Supplementation significantly decreased the energy content of the BBH bread samples compared to the control. The moisture content was significantly increased when the supplementation level was above $11 \%$ and reached the highest value at $21 \%$. There was no significant difference of moisture content between $11 \%$ and $21 \%$. This result is attributed to moisture loss during baking which agrees with the weight loss data shown in Table 3.

There was a significant decreasing trend in proteins and available carbohydrates of fortified breads compared to the control. Regarding total sugar content, there was a reduction in fortified breads compared to the control with the highest reduction seen at $31 \%$. These reductions are indicative of a less extended caramelization process and Maillard reactions, therefore, resulting in decreased crust browning in the fortified breads.

The total fat content of fortified breads ranged from 2.81 to $3.60 \mathrm{~g} / 100 \mathrm{~g}$. The total fat content was significantly decreased above $11 \%$ fortification compared to the control. A significant reduction in saturated and monounsaturated fat content was observed in fortified breads compared to the control bread. There was also a decreasing trend in polyunsaturated fat contents in fortified breads but no significant difference between $11 \%$ and $21 \%$.

There was a non-incremental effect on sodium content of bread samples. Compared with the control, sodium was significantly higher in $11 \%$ and $31 \%$ fortification levels but lower in the $21 \%$ treatment. This variable result could be attributed to the uneven blending of dry ingredients during breadmaking. The ash content of bread samples ranged from 1.74 to $2.10 \mathrm{~g} / 100 \mathrm{~g}$ with the $31 \%$ treatment having the highest value. This indicates that $\mathrm{BBH}$ contains minerals which may attribute to the increase in the ash content.

The total DF content of fortified breads ranged from 8.53 to $19.19 \mathrm{~g} / 100 \mathrm{~g}$ corresponding to an increase in fiber of up to fivefold from the control value. The increase of DF was statistically significant among bread samples. In the UK, the daily recommended DF intake for adults is $30 \mathrm{~g} /$ day [35]. To contribute to this by consuming one portion of bread $(80 \mathrm{~g}), 11 \%, 21 \%, 31 \%$ replacement contribute $23 \%, 38 \%$ and $51 \%$ of the daily intake, respectively. Notably, two portions of $31 \%$ bread can provide the daily intake of DF, not necessarily at one eating occasion. Previous studies have shown that at similar fortification levels ( $30 \%$ replacement of white flour with coarse or fine wheat bran), the total $\mathrm{DF}$ reached its highest value of $18.47 \mathrm{~g} / 100 \mathrm{~g}$ bread [36]. This means that $\mathrm{BBH}$ addition can be used similarly to wheat bran for bread fortification purposes.

The proximate composition of bread samples showed that the addition of $\mathrm{BBH}$ provides better nutritional quality with notably increased DF content. Similar effects were revealed when bakery products were fortified with other crops such as rye flour, rice bran and pineapple fiber $[21,24,37]$. 
Table 5. Proximate composition of control bread, and $11 \%, 21 \%$ and $31 \%$ of $\mathrm{BBH}$ fortified breads.

\begin{tabular}{|c|c|c|c|c|c|c|c|c|c|c|c|c|c|}
\hline \multirow{2}{*}{ Bread Type } & \multicolumn{2}{|c|}{ Energy } & \multirow{2}{*}{$\begin{array}{l}\text { Protein } \\
(\mathrm{g} / 100 \mathrm{~g})\end{array}$} & \multirow{2}{*}{$\begin{array}{l}\text { Available Carbohydrates } \\
\qquad(\mathrm{g} / 100 \mathrm{~g})\end{array}$} & \multirow{2}{*}{$\begin{array}{l}\text { Total Sugars } \\
(\mathrm{g} / 100 \mathrm{~g})\end{array}$} & \multicolumn{4}{|c|}{ Fat $(\mathrm{g} / \mathbf{1 0 0} \mathrm{g})$} & \multirow{2}{*}{$\begin{array}{l}\text { Dietary Fibre } \\
\quad(\mathrm{g} / 100 \mathrm{~g})\end{array}$} & \multirow{2}{*}{$\begin{array}{l}\text { Sodium } \\
(\mathrm{mg} / 100 \mathrm{~g})\end{array}$} & \multirow{2}{*}{$\begin{array}{l}\text { Moisture } \\
(\mathrm{g} / 100 \mathrm{~g})\end{array}$} & \multirow{2}{*}{ Ash $(\mathrm{g} / 100 \mathrm{~g})$} \\
\hline & Kcal/100 g & $\mathrm{kJ} / 100 \mathrm{~g}$ & & & & Total Fat & Saturates & Mono-Unsaturates & Poly-Unsaturates & & & & \\
\hline Control & $269 \pm 0.71^{a}$ & $1133 \pm 4.24^{\mathrm{a}}$ & $10.07 \pm 0.08^{\mathrm{a}}$ & $45.67 \pm 0.18^{\mathrm{a}}$ & $1.06 \pm 0.01^{\mathrm{a}}$ & $4.23 \pm 0.01^{\mathrm{a}}$ & $1.33 \pm 0.01^{\mathrm{a}}$ & $1.81 \pm 0.01^{\mathrm{a}}$ & $0.92 \pm 0.00^{\mathrm{a}}$ & $3.62 \pm 0.06^{\mathrm{a}}$ & $521 \pm 3.54^{\mathrm{a}}$ & $34.68 \pm 0.18^{\mathrm{a}}$ & $1.74 \pm 0.03^{a}$ \\
\hline $11 \%$ & $244 \pm 1.41^{b}$ & $1029 \pm 9.19^{b}$ & $9.12 \pm 0.16^{b}$ & $39.56 \pm 0.70^{b}$ & $0.71 \pm 0.01^{\mathrm{b}}$ & $3.60 \pm 0.05^{b}$ & $1.13 \pm 0.02^{b}$ & $1.55 \pm 0.02^{b}$ & $0.77 \pm 0.01^{b}$ & $8.53 \pm 0.56^{b}$ & $525 \pm 2.12^{b}$ & $37.31 \pm 0.28^{\mathrm{b}}$ & $1.90 \pm 0.03^{b}$ \\
\hline $21 \%$ & $223 \pm 0.71^{c}$ & $935 \pm 1.41^{\mathrm{c}}$ & $8.19 \pm 0.05^{c}$ & $32.78 \pm 0.24^{c}$ & $0.73 \pm 0.00^{b}$ & $3.31 \pm 0.06^{b}$ & $1.04 \pm 0.01^{c}$ & $1.43 \pm 0.02^{c}$ & $0.70 \pm 0.01^{b}$ & $14.53 \pm 0.06^{c}$ & $494 \pm 0.71^{c}$ & $39.57 \pm 0.21^{\mathrm{c}}$ & $1.64 \pm 0.01^{c}$ \\
\hline $31 \%$ & $209 \pm 0.00^{d}$ & $876 \pm 0.00^{d}$ & $7.60 \pm 0.06^{d}$ & $28.82 \pm 0.23^{\mathrm{d}}$ & $0.39 \pm 0.01^{c}$ & $2.81 \pm 0.03^{c}$ & $0.88 \pm 0.01^{\mathrm{d}}$ & $1.20 \pm 0.01^{\mathrm{d}}$ & $0.61 \pm 0.01^{\mathrm{c}}$ & $19.19 \pm 0.22^{d}$ & $533 \pm 1.41^{b}$ & $39.50 \pm 0.11^{\mathrm{c}}$ & $2.10 \pm 0.03^{d}$ \\
\hline
\end{tabular}

Data are expressed as mean \pm SD. Means with different letters within each column are significantly different $(p<0.05)$. 


\subsubsection{Gluten Quantification}

The total gluten content, determined by G12 competitive ELISA assay, is expressed in parts per million (ppm) per loaf and milligram (mg) per $50 \mathrm{~g}$ serving size of bread. The G12 monoclonal antibody can specifically recognize the QPQLPY present in a toxic 33-mer peptide, which is the main immunodominant toxic peptide that causes celiac disease (CD) [2]. The G12 antibody was useful in detecting gluten-relevant peptides due to its sensitivity and epitope preferences, thus reducing the potential toxicity of food for patients with CD [38].

Although gluten content was still high after the addition of $\mathrm{BBH}$, there was a reducing trend with increasing fortification levels. There was no significant difference in gluten content between control bread and $11 \% \mathrm{BBH}$ breads, but a significant reduction occurred when the fortification level was above $21 \%$ (Table 6). The 31\% BBH bread showed the lowest gluten content (7259.00 \pm 748.00 ppm per loaf; $2335.00 \pm 240.51 \mathrm{mg} / 50 \mathrm{~g}$ serving size). Compared with the control, gluten depletion was calculated to be $8 \%, 31 \%$ and $62 \%$ per loaf for breads with $11 \%, 21 \%$ and $31 \% \mathrm{BBH}$, respectively. The observed reduction of gluten at high fortification levels $(31 \%)$, cannot be attributed only to the dilution of gluten content with BBF addition, but there may be an additional effect. Increasing by $10 \%$ the BBH in the bread recipe (from $21 \%$ to $31 \%$ ), the amount of gluten depleted doubled (from $31 \%$ to $62 \%$ ). This effect may be ascribed to interactions between BBH DF and gluten proteins, which limited gluten availability. A crucial step during bread making is the crosslinking of gluten proteins with disulfide bonds to ensure the formation of a viscous dough. Dietary fiber could disrupt the formation of intermolecular disulphide bonds between gluten molecules by forming protein-polysaccharide complexes, thereby decreasing gluten protein cross-linking [39].

Table 6. Gluten content of control bread, and $11 \%, 21 \%$ and $31 \%$ of BBH fortified breads.

\begin{tabular}{cccc}
\hline Bread Type & Gluten (Ppm Per Loaf) & $\begin{array}{c}\text { Gluten }(\mathbf{m g} / \mathbf{5 0} \mathbf{g} \\
\text { Serving Size) }\end{array}$ & $\begin{array}{c}\text { \% Depletion in Gluten } \\
\text { Per Loaf }\end{array}$ \\
\hline Control & $18903.00 \pm 11.00^{\mathrm{a}}$ & $6246.00 \pm 3.60^{\mathrm{a}}$ & 0.00 \\
$11 \%$ & $17420.00 \pm 107.00^{\mathrm{a}}$ & $5712.00 \pm 35.11^{\mathrm{a}}$ & -8.00 \\
$21 \%$ & $13107.00 \pm 523.00^{\mathrm{b}}$ & $4229.00 \pm 168.76^{\mathrm{b}}$ & -31.00 \\
$31 \%$ & $7259.00 \pm 748.00^{\mathrm{c}}$ & $2335.00 \pm 240.51^{\mathrm{c}}$ & -62.00 \\
\hline
\end{tabular}

Data are expressed as mean \pm SD. Means with different letters in the same row are significantly different $(p<0.05)$.

\section{Conclusions}

Overall, this proof of concept study showed that BBH could be effectively used to produce high-fiber breads and lower gluten contents. Among the breads supplemented with $\mathrm{BBH}(11 \%, 21 \%$, $31 \%), 11 \%$ fortification had minimum adverse effects on physical properties and texture profiles. On the other hand, fortification at $31 \%$ produced breads with the most desired nutritional profile. Approximately two slices of BBH-containing bread (156 g) at 31\% replacement of white flour contain $30 \mathrm{~g}$ of DF, which corresponds to the recommended daily DF intake. However, based on the findings of this study, the amount of BBH used to replace white flour in the recipe needs to be lower than $21 \%$ to compensate for significant adverse effects on bread texture and volume. Additional work is needed to elucidate the interactions among the dough components including wheat proteins and fiber polysaccharides, and to better understand the effect of $\mathrm{BBH}$ on the rheological and sensory properties of the BBH-fortified dough, in order to optimize bread recipes and improve quality attributes.

Author Contributions: Conceptualization, V.R. (Viren Ranawana) and V.R. (Vassilios Raikos); methodology, Q.N., H.E.H., N.J.H. and D.S.; formal analysis, Q.N.; writing—original draft preparation, Q.N. and V.R. (Vassilios Raikos); writing-review and editing, all authors; visualization, Q.N.; supervision, V.R. (Vassilios Raikos); project administration, Q.N. All authors have read and agreed to the published version of the manuscript.

Funding: This work is part of the Strategic Research Programme 2016-2021 and is funded by the Scottish Government's Rural and Environment Science and Analytical Services Division (RESAS). 
Acknowledgments: Microscopy was performed in the Microscopy and Histology Core Facility at the University of Aberdeen.

Conflicts of Interest: The authors declare no conflict of interest. The funders had no role in the design of the study; in the collection, analyses, or interpretation of data; in the writing of the manuscript, or in the decision to publish the results.

\section{References}

1. Yano, H. Recent practical researches in the development of gluten-free breads. NPJ Sci. Food $2019,3,7$. [CrossRef] [PubMed]

2. Gil-Humanes, J.; Piston, F.; Altamirano-Fortoul, R.; Real, A.; Comino, I.; Sousa, C.; Rosell, C.M.; Barro, F. Reduced-gliadin wheat bread: An alternative to the gluten-free diet for consumers suffering gluten-related pathologies. PLoS ONE 2014, 9, e90898. [CrossRef] [PubMed]

3. Rosell, C.M. The science of doughs and bread quality. In Flour and Breads and Their Fortification in Health and Disease Prevention; Preedy, V.R., Watson, R.R., Patel, V.B., Eds.; Elsevier: Amsterdam, The Netherlands, 2011; pp. 3-14.

4. Blandino, M.; Locatelli, M.; Sovrani, V.; Coisson, J.D.; Rolle, L.; Travaglia, F.; Giacosa, S.; Bordiga, M.; Scarpino, V.; Reyneri, A.; et al. Progressive pearling of barley kernel: Chemical characterization of pearling fraction and effect of their inclusion on the nutritional and technological properties of wheat bread. J. Agric. Food Chem. 2015, 63, 5875-5884. [CrossRef] [PubMed]

5. Elleuch, M.; Bedigian, D.; Roiseux, O.; Besbes, S.; Blecker, C.; Attia, H. Dietary fibre and fibre-rich by-products of food processing: Characterisation, technological functionality and commercial applications: A review. Food Chem. 2011, 124, 411-421. [CrossRef]

6. Peerajit, P.; Chiewchan, N.; Devahastin, S. Effects of pretreatment methods on health-related functional properties of high dietary fibre powder from lime residues. Food Chem. 2012, 132, 1891-1898. [CrossRef]

7. Turco, V.L.; Potorti, A.G.; Rando, R.; Ravenda, P.; Dugo, G.; Di Bella, G. Functional properties and fatty acids profile of different beans varieties. Nat. Prod. Res. 2016, 30, 1-6. [CrossRef]

8. Carmo, C.S.D.; Silventoinen, P.; Nordgård, C.T.; Poudroux, C.; Dessev, T.; Zobel, H.; Holtekjølen, A.K.; Draget, K.I.; Holopainen-Mantila, U.; Knutsen, S.H.; et al. Is dehulling of peas and faba beans necessary prior to dry fractionation for the production of protein-and starch-rich fractions? Impact on physical properties, chemical composition and techno-functional properties. J. Food Eng. 2020, 278, 109937. [CrossRef]

9. Fendri, L.B.; Chaari, F.; Maaloul, M.; Kallel, F.; Abdelkafi, L.; Ellouz, C.S.; Ghribi-Aydi, D. Wheat bread enrichment by pea and broad bean pods fibers: Effect on dough rheology and bread quality. LWT 2016, 73, 584-591. [CrossRef]

10. Encina-Zelada, C.R.; Cadavez, V.; Monteiro, F.; Teixeira, J.A.; Gonzales-Barron, U. Combined effect of xanthan gum and water content on physicochemical and textural properties of gluten-free batter and bread. Food Res. Int. 2018, 111, 544-555. [CrossRef]

11. Pathak, D.; Majumdar, J.; Raychaudhuri, U.; Chakraborty, R. Characterisation of physicochemical properties in whole wheat bread after incorporation of ripe mango peel. J. Food Meas. Charact. 2016, 10, 554-561. [CrossRef]

12. Food and Agricultural Organization of the United Nations. Food Energy: Methods of Analysis and Conversion Factors; Food and Agricultural Organization of the United Nations: Rome, Italy, 2003.

13. Lee, S.C.; Prosky, L.; De Vries, J.W. Determination of Total, Soluble, and Insoluble Dietary Fiber in Foods-Enzymatic-Gravimetric Method, MES-TRIS Buffer: Collaborative Study. J. AOAC Int. 1992, 75, 396-416. [CrossRef]

14. Englyst, H.N.; Hudson, G.J. Colorimetric method for routine measurement of dietary fiber as non-starch polysaccharides. A comparison with gas-liquid chromatography. Food Chem. 1987, 24, 63-76. [CrossRef]

15. Awika, J.M. Effect of bioactive components on dough rheology, baking and extrusion. In Fruit and Cereal Bioactives: Sources, Chemistry, and Applications; Tokusoglu, O., Hall, C.A., III, Eds.; CRC Press: New York, NY, USA, 2011; pp. 337-344. 
16. Hemdane, S.; Jacobs, P.J.; Dornez, E.; Verspreet, J.; Delcour, J.A.; Courtin, C.M. Wheat (Triticum aestivum L.) Bran in bread making: A critical review. Compr. Rev. Food Sci. Food Saf. 2016, 15, 28-42. [CrossRef]

17. Gelroth, J.; Ranhotra, G.S. Food uses of fibre. In Handbook of Dietary Fibre; Cho, S.S., Dreher, M.L., Eds.; Marcel Dekker: New York, NY, USA, 2001; pp. 435-449.

18. Rosell, C.M.; Rojas, J.A.; Barber, C.B.D. Influence of hydrocolloids on dough rheology and bread quality. Food Hydrocoll. 2001, 15, 75-81. [CrossRef]

19. Wang, M.; Hamer, R.J.; van Vliet, T.; Oudgenoeg, G. Interaction of water extractable pentosans with gluten protein: Effect on dough properties and gluten quality. J. Cereal Sci. 2002, 36, 25-37. [CrossRef]

20. Sivam, A.S.; Sun-Waterhouse, D.; Quek, S.; Perera, C.O. Properties of bread dough with added fiber polysaccharides and phenolic antioxidants: A review. J. Food Sci. 2010, 75, R163-R174. [CrossRef]

21. Tuncel, N.B.; Yilmaz, N.; Kocabiyik, H.; Uygur, A. The effect of infrared stabilised rice bran substitution on physicochemical and sensory properties of pan breads: Part I. J. Cereal Sci. 2014, 59, 155-161. [CrossRef]

22. Ranawana, V.; McDougall, G.; Hayward, N.; Raikos, V. Vicia faba hull: A novel source of fibre, and a functional food with antidiabetic properties. Proc. Nutr. Soc. 2020, 79, E299. [CrossRef]

23. Stevenson, L.; Phillips, F.; O'Sullivan, K.; Walton, J. Wheat bran: Its composition and benefits to health, a European Perspective. Int. J. Food Sci. Nutr. 2012, 63, 1001-1013. [CrossRef]

24. Chareonthaikij, P.; Uan-On, T.; Prinyawiwatkul, W. Effects of pineapple pomace fibre on physicochemical properties of composite flour and dough, and consumer acceptance of fibre-enriched wheat bread. Int. J. Food Sci. Technol. 2016, 51, 1120-1129. [CrossRef]

25. Zhang, D.; Moore, W.R. Wheat bran particle size effects on bread baking performance and quality. J. Sci. Food Agric. 1999, 79, 805-809. [CrossRef]

26. Dhen, N.; Rejeb, I.B.; Boukhris, H.; Damergi, C.; Gargouri, M. Physicochemical and sensory properties of wheat-apricot kernels composite bread. LWT-Food Sci. Technol. 2018, 95, 262-267. [CrossRef]

27. Anil, M. Using of hazelnut testa as a source of dietary fiber in breadmaking. J. Food Eng. 2007, 80, 61-67. [CrossRef]

28. Purils, E. Bread baking: Technological considerations based on process modelling and simulation. J. Food Eng. 2011, 103, 92-102. [CrossRef]

29. Bouaziz, F.; Abdeddayem, A.B.; Koubaa, M.; Ghorbel, R.E.; Chaabouni, S.E. Date seeds as a natural source of dietary fibers to improve texture and sensory properties of wheat bread. Foods 2020, 9, 737. [CrossRef]

30. Laukova, M.; Kohajdova, Z.; Karovicova, J.; Kuchtova, V.; Minarovicova, L.; Tomasikova, L. Effects of cellulose fiber with different fiber length on rheological properties of wheat dough and quality of baked rolls. Food Sci. Technol. Int. 2017, 23, 490-499. [CrossRef]

31. Kowalczewski, P.L.; Walkowiak, K.; Masewicz, L.; Duda, A.; Poliszko, N.; Rozanska, M.B.; Jezowski, P.; Tomkowiak, A.; Mildner-Szkudlarz, S.; Baranowska, H.M. Wheat bread enriched with raspberry and strawberry oilcakes: Effects on proximate composition, texture and water properties. Eur. Food Res. Technol. 2019, 245, 2591-2600. [CrossRef]

32. Armero, E.; Collar, C. Texture properties of formulated wheat doughs: Relationships with dough and bread technological quality. Zeitschrift für Lebensmitteluntersuchung und-Forschung A 1997, 204, 136-145. [CrossRef]

33. Aydogdu, A.; Sumnu, G.; Sahin, S. Effects of addition of different fibers on rheological characteristics of cake batter and quality of cakes. J. Food Sci. Technol. 2018, 55, 667-677. [CrossRef]

34. Hoehnel, A.; Bez, J.; Petersen, I.L.; Amarowicz, R.; Juskiewicz, J.; Arendt, E.K.; Zannini, E. Enhancing the nutritional profile of regular wheat bread while maintaining technological quality and adequate sensory attributes. Food Funct. 2020, 11, 4732. [CrossRef]

35. Macdiarmid, J.I.; Clark, H.; Whybrow, S.; Ruiter, H.D.; McNeil, G. Assessing national nutrition security: The UK reliance on imports to meet population energy and nutrient recommendation. PLoS ONE 2018, 13, e0192649. [CrossRef] [PubMed]

36. Sidhu, J.S.; Al-Hooti, S.N.; Al-Saqer, J.M. Effect of adding wheat bran and germ fractions on the chemical composition of high-fiber toast bread. Food Chem. 1999, 67, 365-371. [CrossRef]

37. Kolodziejczyk, P.; Michniewicz, J.; Buchowski, M.S.; Paschke, H. Effects of fibre-rich rye milling fraction on the functional properties and nutritional quality of wholemeal rye bread. J. Food Sci. Technol. 2020, 57, 222-232. [CrossRef] [PubMed] 
38. Moron, B.; Bethune, M.T.; Comino, I.; Manyani, H.; Ferragud, M.; Lopez, M.C.; Cebolla, A.; Khosla, C.; Sousa, C. Toward the assessment of food toxicity for celiac patients: Characterisation of monoclonal antibodies to a main immunogenic gluten peptide. PLoS ONE 2008, 3, e2294. [CrossRef]

39. Adams, G.G.; Kok, S.M.; Imran, S.; Harding, S.E.; Ilyas, M.; Tatham, A.S. The interaction of dietary fibres with disulphide bonds (S-S) and a potential strategy to reduce the toxicity of the gluten proteins in coeliac disease. Biotechnol. Genet. Eng. 2012, 28, 115-130. [CrossRef]

(C) 2020 by the authors. Licensee MDPI, Basel, Switzerland. This article is an open access article distributed under the terms and conditions of the Creative Commons Attribution (CC BY) license (http://creativecommons.org/licenses/by/4.0/). 